\title{
PENGARUH JENIS ADSORBEN PADA EFEKTIFITAS PENURUNAN KANDUNGAN Pb AIR LIMBAH RECYCLE AKI BEKAS
}

\author{
ROHMAT MUFTI ALI ${ }^{1)}$, TRI YUNI HENDRAWATI'), \& ISMIYATI $^{3)}$ \\ 1,2,3) Jurusan Teknik Kimia, Fakultas Teknik, \\ Universitas Muhammadiyah Jakarta, Indonesia \\ ${ }^{1)}$ Email: rohmat.m.a@gmail.com
}

\begin{abstract}
ABSTRAK
Pengolahan air limbah Aki bekas recycle dilakukan karena menghasilkan limbah yang mengandung $\mathrm{Pb}$ dan bersifat asam pada air cucian limbah. Untuk hal tersebut perlu dilakukan penelitian dalam menurunkan kandungan $\mathrm{Pb}$ pada limbah recycle aki bekas. Tujuan penelitian ini adalah mendapatkan pengaruh jenis adsorben dan persentase massa adsorben terhadap penurunan kandungan $\mathrm{Pb}$. Penelitian ini dilakukan beberapa tahap proses, yaitu pembuatan air limbah imitasi aki bekas, persiapan adsorben dan proses adsorpsi batch. Proses awal penelitian membuat air limbah imitasi aki bekas dengan proses perendaman aki bekas dengan air 4 liter selama 10 hari. Penyiapan adsorben dengan perlakuan kimia fisika pada karbon aktif dan zeolite. Setelah proses perendaman dengan plat $\mathrm{Pb}$ selama 10 hari adsorben siap digunakan. Proses adsorpsi batch dilakukan menggunakan sampel air limbah imitasi aki bekas sebanyak $100 \mathrm{ml}$ diaduk dengan kecepatan $150 \mathrm{rpm}$ selama 1 jam dengan variasi jenis adsorben zeolite dan karbon aktif. Variabel persentase massa adsorben yaitu 0\%, $5 \%$ $(\mathrm{m} / \mathrm{v}), 10 \%(\mathrm{~m} / \mathrm{v}), 15 \%(\mathrm{~m} / \mathrm{v}), 20 \%(\mathrm{~m} / \mathrm{v})$, dan $25 \%(\mathrm{~m} / \mathrm{v})$. Pada adsorbsi dengan zeolite menunjukkan hasil penurunan kadar pb dari $8.02 \mathrm{mg} / \mathrm{L}$ menjadi $1.667 \mathrm{mg} / \mathrm{L}$. sedangkan untuk karbon aktif menunjukkan hasil penurunan kadar $\mathrm{Pb}$ dari $8.02 \mathrm{mg} / \mathrm{L}$ menjadi $0.239 \mathrm{mg} / \mathrm{L}$. Hasil yang didapat dari penelitian ini adalah kadar penurunan $\mathrm{Pb}$ terbaik pada jenis adsorben karbon aktif dengan persentase adsorben $25 \%(\mathrm{~m} / \mathrm{v})$ terjadi penurunan kandungan $\mathrm{Pb}$ dari 8.02 $\mathrm{mg} / \mathrm{L}$ menjadi $0.239 \mathrm{mg} / \mathrm{L}$.
\end{abstract}

Kata Kunci: Adsorben, Limbah Recycle, Karbon Aktif, Lingkungan Hidup.

\section{PENDAHULUAN}

Berbagai usaha telah banyak dilakukan agar kehadiran pencemaran terhadap air dapat dihindari atau setidaknya diminimalkan [1]. Masalah pencemaran serta efisiensi penggunaan sumber air merupakan masalah pokok. Hal ini mengingat keadaan perairan-alami di banyak negara yang cenderung menurun, baik kualitas maupun kuantitasnya [5]. Pb adalah logam berat yang mempunyai afinitas yang paling tinggi terhadap belerang dan menyerang ikatannya didalam enzim. Sebagai logam berat, $\mathrm{Pb}$ digolongkan ke dalam bahan pencemar yang berbahaya [6]. Pb berada didalam air dalam bentuk $\mathrm{Pb}(\mathrm{OH})_{2}$. Logam $\mathrm{Pb}$ banyak sekali digunakan pada industri, bensin, aki dan pengerjaan pemipaan. Aki bertimbal merupakan sumber di muka bumi [4]. Keba- nyakan $\mathrm{Pb}$ yang ada di bumi memasuki sistem perairan alam, dan terakumulasi yang pada akhirnya bisa masuk ke dalam tubuh hewan dan manusia. Jika terserap ke dalam tubuh manusia, timbal $(\mathrm{Pb})$ dapat menyebabkan kecerdasan anak menurun, pertumbuhan badan terhambat, bahkan dapat menimbulkan kelumpuhan. Gejala keracunan logam $\mathrm{Pb}$ lainnya: mual, anemia, dan sakit perut $[1,2,3,4]$. Kandungan $\mathrm{Pb}$ air limbah recyce aki bekas yang selama ini sering dibuang begitu saja kealam tentunya perlu diperhatikan karena akan mencemari lingkungan, sehingga perlu dilakukan penelitian bagaimana mereduksi kandungan $\mathrm{Pb}$ air limbah recycle aki bekas. Salah satu cara adalah dengan mengadsorpsi. Adsorpsi dipilih karena merupakan metode yang relatif sederhana dan dapat mengguna- 
kan adsorben bahan alam dari biomasa. Pada penelitian ini, karbon aktif dan zeolite yang digunakan. Karbon aktif dan zeolite adalah bahan yang baik sebagai adsorben karena mempunyai daya adsorpsi yang baik. Struktur dan unsur pembangunnya, adsorben dapat digolongkan menjadi dua yaitu adsorben tidak berpori (non porous adsorbents) dan adsorben berpori (porous adsorbents). (Mulyati, 2006). Berdasarkan uji pendahuluan nilai parameter tersebut yaitu, $\mathrm{Pb}$ (timbal) air limbah aki bekas $8.02 \mathrm{mg} / \mathrm{L}$, $\mathrm{pH} 2$, densitas $1.036 \mathrm{grm} / \mathrm{cm}^{3}$. Peraturan Menteri Lingkungan Hidup Republik Indonesia No.5 Tahun 2014 Nilai parameter $\mathrm{Pb}$ yang diperbolehkan yaitu 0,3 $\mathrm{mg} / \mathrm{L}$. Dalam sebuah penelitian Adsorben zeolite mampu menurunkan logam yang terkandung dalam air lindi yaitu $\mathrm{Fe}$ sebesar $62,728 \%$ dari $12,668 \mathrm{mg} / \mathrm{l}$ menjadi $7,948 \mathrm{mg} / \mathrm{l}$ (Larasati. dkk. 2014) serta logam Pb sebesar $73,75 \%$ dari $2,29 \mathrm{mg} / \mathrm{l}$ menjadi $0,39 \mathrm{mg} / \mathrm{l}$ (Susanawati, dkk. 2011). Menurut penelitian Fajarwati, dkk (2012) karbon aktif mampu menurunkan logam besi sebesar $59,64 \%$ dari $3,03 \mathrm{mg} / \mathrm{l}$ menjadi $1,22 \mathrm{mg} / \mathrm{l}$. Oleh karena itu pada penelitian ini akan dilakukan pengolahan limbah recycle aki bekas dengan proses adsorpsi menggunakan zeolit dan karbon aktif guna menurunkan parameter tersebut. Tujuan penelitian ini adalah mendapatkan pengaruh jenis adsorben dan persentase massa adsorben terhadap penurunan kandungan $\mathrm{Pb}$.

\section{METODE PENELITIAN}

Penelitian ini dilakukan di Laboratorium Kimia Fisika, Jurusan Teknik Kimia, Fakultas Teknik, Universitas Muhammadiyah Jakarta. Bahan: karbon aktif, zeolit, Air limbah aki bekas, $\mathrm{HCl}, \mathrm{NaOH}$. Alat yang digunakan: bak perendam aki bekas, grinding, vibrator screen, kertas Saring, batang pengaduk, spatula, labu ukur, labu erlenmeyer, gelas beaker, neraca analitik, hot plate, oven, vacum filter, kertas lakmus, piknometer. Dalam percobaan ini dilakukan beberapa tahap proses, yaitu perendaman, persiapan adsorben dan proses penelitian adsorpsi batch. Adsorpsi dengan system batch dilakukan dalam skala laboratorium. Proses awal sebelum memulai proses penelitian dilakukan proses perendaman dimana air limbah aki sebagai sampel didiamkan selama 10 hari. Selama proses perendaman berlangsung, maka dilakukan persiapan adsorben yang akan digunakan antara lain karbon aktif dan zeolit yang berfungsi untuk menurunkan timbal $\mathrm{Pb}$ pada air limbah recycle aki bekas. Setelah proses perendaman plat $\mathrm{Pb}$ aki bekas 10 hari adsorben siap dipakai, maka dilakukan proses adsorpsi batch dimana proses yang dilakukan menggunakan sampel air limbah aki sebanyak $100 \mathrm{ml}$ yang akan diserap timbalnya menggunakan adsorben zeolit dan karbon aktif. Proses dilakukan selama 60 menit kecepatan $150 \mathrm{rpm}$, dengan variasi jenis adsorben, penambahan adsorben $0 \%, 5$ $\%(\mathrm{~m} / \mathrm{v}), 10 \%(\mathrm{~m} / \mathrm{v}), 15 \%(\mathrm{~m} / \mathrm{v}), 20 \%$ $(\mathrm{m} / \mathrm{v})$, dan $25 \%(\mathrm{~m} / \mathrm{v})$. Kemudian, dilakukan metode analisa penurunan kandungan $\mathrm{Pb}$ timbal, densitas dan $\mathrm{pH}$. Kualitas air limbah recycle aki bekas dibandingkan dengan Peraturan Menteri Lingkungan Hidup Republik Indonesia No.5 Tahun 2014 tentang Baku Mutu Air Limbah. Analisis data dilakukan, dimana kualitas air limbah recycle aki bekas yang telah dilakukan pengolahan dibandingkan dengan kualitas air limbah recycle aki bekas sebelum dilakukan pengolahan untuk mendapatkan nilai efektivitas yang disajikan dalam bentuk tabel.

Proses Adsorpsi

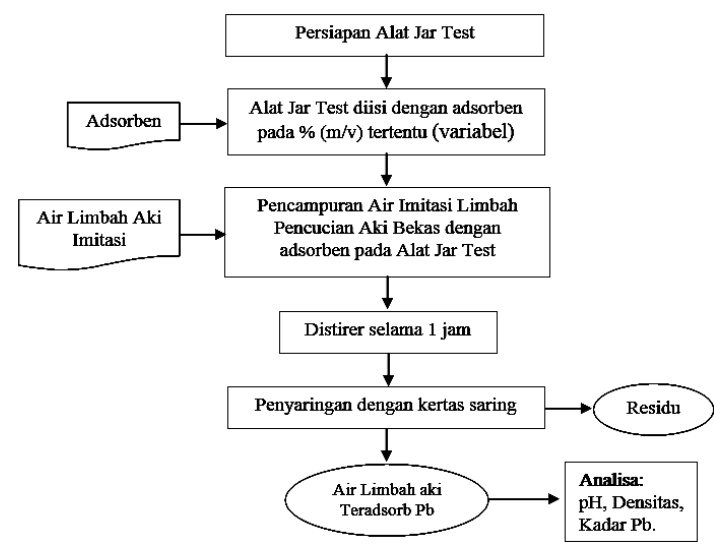

Gambar 1. Diagram Alir Penelitian

\section{HASIL DAN DISSCUSSION}

1. Prosentase Penurunan kandungan $\mathrm{Pb}$

Penelitian ini dilakukan dengan dua jenis variabel; yaitu jenis adsorben (Zeolit dan Karbon aktif) dan konsentrasi adsorben 0\%, 5 $\%(\mathrm{~m} / \mathrm{v}), 10 \%(\mathrm{~m} / \mathrm{v}), 15 \%(\mathrm{~m} / \mathrm{v}), 20 \%$ $(\mathrm{m} / \mathrm{v})$, dan $25 \%(\mathrm{~m} / \mathrm{v})$. dengan volume sampel limbah aki bekas pada $100 \mathrm{ml}$. Limbah aki yang diperoleh dari proses adsorpsi dibedakan antara limbah awal dan hasil proses Limbah aki. Adsorben yang digunakan dalam proses adsorpsi pada pengolahan air limbah imitasi 
aki bekas adalah karbon aktif dan zeolit. Karbon aktif dan zeolit yang diaktivasi secara fisika dan kimia yaitu dengan pencucian, pemanasan dan aktivasi dengan $\mathrm{NaOH}$ untuk karbon aktif dan $\mathrm{HCl}$ untuk zeolit. Aktifasi karbon dan zeolite agar pori-pori terbuka dan memiliki rongga, dimana rongga tersebut mampu menyerap sejumlah molekul-molekul yang ukurannya lebih kecil atau sama dengan ukuran rongga adsorben tersebut (Khimayah, 2015).

Table 1. Hasil penurunan kandungan $\mathrm{Pb}$ dari limbah aki bekas pada jenis adsorben dan konsentrasi adsorben

\begin{tabular}{|c|l|c|}
\hline No. & Adsorben \% (m/v) & Hasil akhir (\%) \\
\hline 1 & Zeolit 0 \% & $100 \%$ \\
\hline 2 & Zeolit 5\% & $37.67 \%$ \\
\hline 3 & Zeolit $10 \%$ & $28.37 \%$ \\
\hline 4 & Zeolit $15 \%$ & $26.48 \%$ \\
\hline 5 & Zeolit 20\% & $21.92 \%$ \\
\hline 6 & Zeolit 25\% & $20.79 \%$ \\
\hline 7 & Karbon aktif 0\% & $100 \%$ \\
\hline 8 & Karbon aktif 5\% & $13.97 \%$ \\
\hline 9 & Karbon aktif $10 \%$ & $7.07 \%$ \\
\hline 10 & Karbon aktif $15 \%$ & $4.70 \%$ \\
\hline 11 & Karbon aktif $20 \%$ & $3.90 \%$ \\
\hline 12 & Karbon aktif $25 \%$ & $2.98 \%$ \\
\hline
\end{tabular}

Data analisis dari efek jenis adsorben dan konsentrasi $\mathrm{Pb}$ pada limbah aki bekas disajikan dalam bentuk grafik yang ditunjukkan pada Gambar 2.

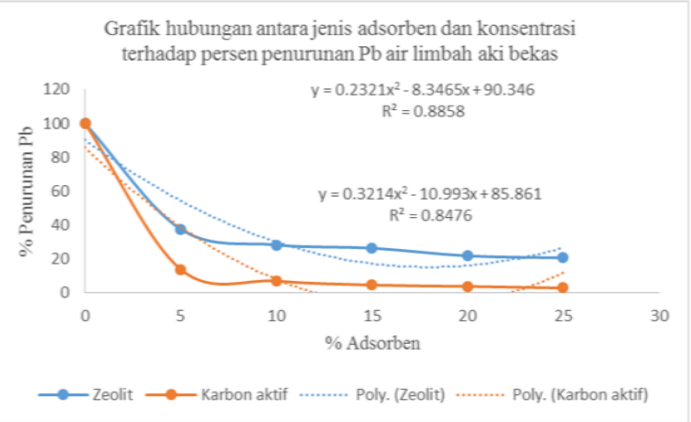

Gambar 2. Hubungan antara jenis adsorben dan konsentrasi terhadap prosentase penurunan kandungan $\mathrm{Pb}$ dalam air limbah aki bekas

Analisis data menggunakan Polinomial Orde 2 untuk mendapatkan korelasi antara jenis adsorben dan konsentrasi terhadap persentase penurunan kandungan $\mathrm{Pb}$ dalam air limbah aki bekas Hasilnya disajikan pada Gambar 2.

Penambahan Karbon aktif menghasilkan $\mathrm{y}=0.3214 \mathrm{x} 2-10.993 \mathrm{x}+85.861$ dengan $\mathrm{R}^{2}=$ 0.8476 , sedangkan Penambahan Zeolit meng- hasilkan $\mathrm{y}=0.2321 \mathrm{x} 2-8.3465 \mathrm{x}+90.346$ dengan $\mathrm{R}^{2}=0.8858$, dengan hasil yang mewakili y dan x mewakili konsentrasi. Angka di atas menunjukkan bahwa semakin banyak adsorben ditambahkan, semakin banyak hasil yang dihasilkan.

Proses adsorpsi yang terjadi pada karbon aktif yaitu proses adsorpsi secara fisika, dimana proses penjerapan ion logam $\mathrm{Pb}^{2+}$ terjadi pada permukaan karbon aktif. Dengan adanya gaya Van Der Waals pada pori-pori karbon aktif maka partikel pencemar yang terdapat pada limbah tertarik dan terperangkap pada pori-pori karbon aktif (Hendra, 2008), sehingga ion logam $\mathrm{Pb}^{2+}$ pada limbah menjadi berkurang [9]. Berdasarkan pada penelitian ini penurunan logam $\mathrm{Pb}$ yang optimum terjadi dari sebesar $8,020 \mathrm{mg} / \mathrm{L}$ menjadi $0,239 \mathrm{mg} / \mathrm{L}(25 \%(\mathrm{~m} / \mathrm{v})$ Karbon aktif. Proses adsorpsi menggunakan zeolit untuk menurunkan ion logam $\mathrm{Pb}^{2+}$ yang terdapat pada limbah aki bekas. Penurunan ion logam $\mathrm{Pb}^{2+}$ dengan proses adsorpsi terjadi karena zeolit dapat berperan sebagai penjerap/adsorben [10]. Zeolit yang diaktivasi bersifat dehidrasi dan akan memiliki pori-pori yang terbuka. Semakin luas pori-pori zeolite maka akan semakin banyak adsorbat yang teradsorpsi (Azamia, 2012). Atom oksigen yang berikatan dengan ion silika yang mempunyai sifat kebasaan yang rendah dan membuat permukaan silika bersifat asam lemah [8]. Atom oksigen 8 pada permukaan silika bebas bereaksi dengan air membetuk grup silanol ( $\mathrm{SiOH})$. Bentuk oksida yang lain juga bebas bereaksi dengan air membentuk hidroksida [7]. Ion $\mathrm{H}+$ pada bentuk hidroksida akan melemah dan mudah lepas dan mengakibatkan ion logam $\mathrm{Pb}^{2+}$ akan terikat dan teradsorpsi secara kuat (Setiaka, dkk. 2010). Hal ini yang menyebabkan kadar $\mathrm{Pb}$ pada limbah menjadi turun dari $8,020 \mathrm{mg} / \mathrm{L}$ menjadi $1,667 \mathrm{mg} / \mathrm{L} 25 \%(\mathrm{~m} / \mathrm{v})$ Zeolit dan masih diatas baku mutu. Sedangkan kation $\mathrm{H}+$ yang terdapat pada permukaan zeolite terlepas dan menyebabkan $\mathrm{pH}$ limbah menjadi asam.

\section{Efek Dari Jenis dan \% Berat Adsorben Pada Hasil}

Hasil dihitung dari membandingkan densitas dari adsorpsi ke Limbah aki itu. Proses adsorpsi berlangsung selama 1 jam dan pada kecepatan tetap $150 \mathrm{rpm}$. Hasil lengkap dari 
hasil dari berbagai jenis dan densitas adsorben disajikan pada Tabel 2 .

Table 2. Densitas limbah baterai pada berbagai jenis dan $\%$ adsorben

\begin{tabular}{|c|l|c|}
\hline No. & Adsorben \% (m/v) & Densitas $\left(\mathbf{g r m} / \mathbf{c m}^{3}\right)$ \\
\hline 1 & Zeolit 0 \% & 1.036 \\
\hline 2 & Zeolit 5\% & 1.0024 \\
\hline 3 & Zeolit 10\% & 1.026 \\
\hline 4 & Zeolit 15\% & 1.0444 \\
\hline 5 & Zeolit 20\% & 1.0456 \\
\hline 6 & Zeolit 25\% & 1.0276 \\
\hline 7 & Karbon aktif 0 \% & 1.036 \\
\hline 8 & Karbon aktif 5\% & 1.026 \\
\hline 9 & Karbon aktif 10\% & 1.0348 \\
\hline 10 & Karbon aktif 15\% & 1.0332 \\
\hline 11 & Karbon aktif 20\% & 1.0404 \\
\hline 12 & Karbon aktif 25\% & 1.036 \\
\hline
\end{tabular}

Analisis data tentang efek densitas dari jenis adsorben dan \% berat pada hasil limbah aki bekas disajikan dalam bentuk grafik yang ditunjukkan pada Gambar 3.

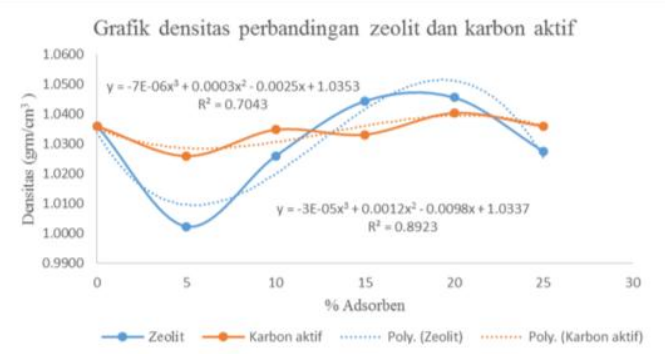

Gambar 3. Efek dari jenis adsorben dan konsentrasi pada densitas dari limbah aki bekas dari proses adsorpsi.

Data dianalisis dengan Polinomial Orde 3 pada Zeolit dan pada Karbon aktif, yang menghasilkan rumus berikut. Penambahan Zeolit menghasilkan $\mathrm{y}=-3 \mathrm{E}-05 \times 3+$ $0.0012 \times 2-0.0098 \mathrm{x}+1.0337$ dengan $\mathrm{R}^{2}=$ 0.8923 , sedangkan penambahan Karbon aktif menghasilkan $\mathrm{y}=-7 \mathrm{E}-06 \times 3+0.0003 \times 2-$ $0.0025 \mathrm{x}+1.0353$ dengan $\mathrm{R}^{2}=0.7043$, di mana y mewakili kepadatan dan $\mathrm{x}$ mewakili konsentrasi dan jenis adsorben.

Pengukuran Limbah aki bekas kepadatan adalah untuk menentukan berat Limbah aki bekas per satuan volume.

Data yang disajikan pada gambar 3 dengan adsorben $5 \%(\mathrm{~m} / \mathrm{v})$ menyebabkan naiknya densitas yang terserap, namun pada adsorben $10-25 \%(\mathrm{~m} / \mathrm{v})$ serapannya relative menurun. Terjadinya peningkatan adsorpsi impuritis pada Adsorben zeolit 5\% (m/v), karena kerapatan sel zeolit dalam larutan sehingga menghasilkan interaksi yang cukup efektif antara pusat aktif dinding sel zeolit.
Selanjutnya adsorpsi impuritis menurun pada zeolit $10-25 \%(\mathrm{~m} / \mathrm{v})$. Hal ini menunjukkan bahwa berat dan jenis adsorben berpengaruh terhadap proses adsorpsi karena semakin bertambahnya berat adsorben, maka nilai densitas teradsorpsi terhadap ion juga semakin meningkat dan mencapai titik jenuh.

\section{Efek dari jenis adsorben dan $p H$}

Pengujian $\mathrm{pH}$ disajikan pada Tabel 3.

Tabel 3. Hasil Pengujian $\mathrm{pH}$ dari jenis adsorben yang berbeda dan $\%(\mathrm{~m} / \mathrm{v})$ Adsorben

\begin{tabular}{|c|l|c|}
\hline No. & Adsorben \% (m/v) & pH \\
\hline 1 & Zeolit 0\% & 2 \\
2 & Zeolit 5\% & 3 \\
3 & Zeolit 10\% & 3 \\
4 & Zeolit 15\% & 3 \\
5 & Zeolit 20\% & 3 \\
6 & Zeolit 25\% & 3 \\
7 & Karbon aktif 0\% & 2 \\
8 & Karbon aktif 5\% & 2 \\
9 & Karbon aktif 10\% & 2 \\
10 & Karbon aktif 15\% & 2 \\
11 & Karbon aktif 20\% & 2 \\
12 & Karbon aktif 25\% & 2 \\
\hline
\end{tabular}

Efek dari jenis adsorben dan \% berat pada $\mathrm{pH}$ limbah aki bekas disajikan dalam bentuk grafik yang ditunjukkan pada Gambar 4.

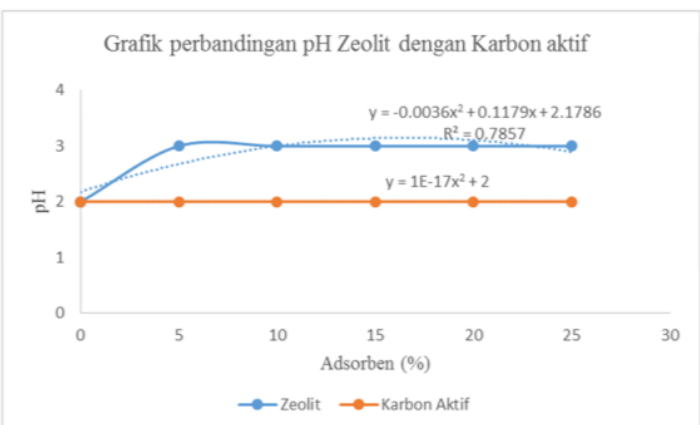

Gambar 4. Efek dari jenis adsorben dan \% berat pada nilai-nilai $\mathrm{pH}$ Limbah Aki bekas dari proses adsorpsi

Hasil pengujian $\mathrm{pH}$ yang dianalisis menggunakan korelasi linear antara konsentrasi jenis adsorben dan nilai-nilai $\mathrm{pH}$. Penambahan Zeolit menghasilkan $\mathrm{y}=-0.0036 \mathrm{x} 2$ $+0.1179 \mathrm{x}+2.1786$ dengan $\mathrm{R}^{2}=0.7857$, sedangkan Karbon aktif menghasilkan $\mathrm{y}=$ $1 \mathrm{E}-17 \mathrm{x} 2+2$, dengan y mewakili $\mathrm{pH}$ dan $\mathrm{x}$ mewakili konsentrasi adsorben.

Gambar 4 menunjukkan bahwa konsentrasi adsorben yang lebih tinggi, semakin tinggi nilai-nilai $\mathrm{pH}$. $\mathrm{pH}$ akan mempengaruhi daya serap permukaan adsorben, tingkat ionisasi, dan spesies yang terserap dalam pro- 
ses adsorpsi [11]. Nilai-nilai $\mathrm{pH}$ juga mempengaruhi kesetimbangan kimia dari adsorbates serta adsorben. Dalam variasi $\mathrm{pH}$ ini, kemungkinan ikatan kimia antara adsorben dan adsorbat dapat terjadi.

\section{KESIMPULAN}

1. Kesimpulan dari penelitian ini adalah:

a. Persentase penurunan kandungan $\mathrm{Pb}$ yang optimum terjadi pada jenis adsorben karbon aktif sebesar $2.98 \%$ dari $8.02 \mathrm{mg} / \mathrm{L}$ menjadi $0.239 \mathrm{mg} / \mathrm{L}$ konsentrasi adsorben $25 \%(\mathrm{~m} / \mathrm{v})$. Sifat fisik $\mathrm{pH}$ dan densitas adsorben zeolit konsentrasi adsorben 5\% (m/v) $\mathrm{pH} 3$ nilai densitas $1.0024 \mathrm{grm} / \mathrm{cm}^{3}$. formula dari Karbon aktif $y=0.3214 x 2-10.993 x$ +85.861 dengan $\mathrm{R}^{2}=0.8476$

b. Hasil penurunan kandungan $\mathrm{Pb}$ dengan adsorben Karbon aktif persentase penurunan $\mathrm{Pb}$ sebesar $2.98 \%$ dari $8.02 \mathrm{mg} / \mathrm{L}$ menjadi $0.239 \mathrm{mg} / \mathrm{L}$ nilai parameter masuk standar yang diujikan berada di baku mutu menurut PERMEN LH No. 5 Th. 2014 dan sifat fisik (densitas, pH) densitas ada perubahan dari 1.0360 $\mathrm{grm} / \mathrm{cm}^{3}$ menjadi $1.0276 \mathrm{grm} / \mathrm{cm}^{3}$ terjadi penurunan massa jenis. $\mathrm{pH}$ masih berada di atas baku mutu tidak efektif dan tidak aman terhadap ambang batas pencemaran lingkungan, $\mathrm{pH}$ perlu dilakukan uji lanjutan dalam pengolahan limbah recycle aki bekas dengan melakukan netralisasi limbah sebelum pengolahan karena $\mathrm{pH}$ limbah recycle aki bekas sangat asam yaitu 2 .

c. Hasil optimal dari penelitian ini adalah dari penambahan karbon aktif dengan konsentrasi $25 \%(\mathrm{~m} / \mathrm{v})$ adsorben karbon aktif dengan hasil penurunan $\mathrm{Pb} 0.239$ $\mathrm{mg} / \mathrm{L}(\mathrm{y}=0.3214 \mathrm{x} 2-10.993 \mathrm{x}+85.861$ dengan $\mathrm{R}^{2}=0.8476$ ), nilai densitas $1.0024 \mathrm{grm} / \mathrm{cm}^{3}(\mathrm{y}=-3 \mathrm{E}-05 \times 3+$ $0.0012 \times 2-0.0098 \mathrm{x}+1.0337$ dengan $\mathrm{R}^{2}$ $=0.8923)$, dan nilai $\mathrm{pH}$ dari $3(\mathrm{y}=-$ $0.0036 \times 2+0.1179 \mathrm{x}+2.1786$ dengan $\mathrm{R}^{2}$ $=0.7857$ ).

\section{Pengakuan}

Dengan selesainya penelitian ini saya mengucapkan terima kasih yang sebesarbesarnya kepada Allah SWT, orang tua, kedua dosen pembimbing yaitu Dr.Ir. Tri Yuni Hendrawati, M.Si yang sudah memberikan dana penelitian dan bimbingannya, Ibu Dr.Ir Ismiyati, MT yang sudah memberikan bimbingannya, dosen magister teknik kimia umj, serta kepada teman-teman S2 Teknik kimia UMJ 2017 dan semua orang yang telah berperan dalam membantu penelitian yang tidak dapat di ucapkan satu persatu. Harapan saya penelitian ini dapat bermanfaat bagi semua dan dapat dipergunakan sebagaimana mestinya.

\section{DAFTAR PUSTAKA}

[1] Azamia, M. 2012. Pengolahan Limbah Cair Laboratorium Kimia Dalam Penurunan Kadar Organik Serta Logam Berat Fe, Mn, Cr Dengan Metode Koagulasi dan Adsorpsi. FMIPA UI: Jakarta.

[2] Fajarwati, I. 2015. Pengolahan Air Tanah Dengan Sistem Multifiltrasi Menggunakan Cangkang Kerang, Zeolit, Dan Karbon Aktif. Jurnal Mahasiswa S1 Teknik Lingkungan: Vol. 1, No. 1. UNTAN: Pontianak.

[3] Furlan FR, da Silva LGdM, Morgado AF, de Souza AAU. Removal of reactive dyes from aqueous solutions using combined coagulation/flocculation and adsorption on activated carbon. Resources, Conservation and Recycling. 2010;54:283-90.

[4] Kristiana I, Joll C, Heitz A. Powdered activated carbon coupled with enhanced coagulation for natural organic matter removal and disinfection byproduct control: Application in a Western Australian water treatment plant. Chemosphere. 2011;83:661-7.

[5] Lee J-W, Choi S-P, Thiruvenkatachari R, Shim W-G, Moon H. Submerged microfiltration membrane coupled with alum coagulation/powdered activated carbon adsorption for complete decolorization of reactive dyes. Water Research. 2006;40:435-44.

[6] Papić S, Koprivanac N, Božić AL, Meteš A. Removal of some reactive dyes from synthetic wastewater by combined $\mathrm{Al}$ (III) coagulation/carbon adsorption 
process. Dyes and Pigments. 2004;62: 291-8.

[7] Hendra, R. 2008. Pembuatan Karbon Aktif Berbahan Dasar Batubara Indonesia Dengan Metode Aktivasi Fisika dan Karakteristiknya. Departemen Teknik Mesin.UI: Jakarta.

[8] Iswanto, W.N.A.; Moelyaningrum, A.D.; dan Pujiati, R.S. 2016. Penurunan Kadar Logam Timbal Pada Limbah Cair Percetakan Dengan Zeolit Alam Teraktivasi (Studi Pada Limbah Cair Percetakan X Jember). Jember.

[9] Khimayah. 2015. Variasi Diameter Zeolit Untuk Menurunkan Kadar Besi (Fe) Pada Air Sumur Gali. Universitas Diponegoro: Semarang.

[10] Nurlina.; Zahra, T.A.; Gusrizal; dan Kartika, I.D. 2015. Efektivitas Penggunanaan Tawas dan Karbon Aktif Pada
Pengolahan Limbah Cair Industri Tahu. Prosiding SEMIRATA 2015 Bidang MIPA BKS-PTN Barat. Hal. 690-699. Universitas Tanjungpura. Pontianak.

[11] Setiaka, J; Ulfin, I; dan Widiastuti, N. 2010. Adsorpsi Ion Logam Cu (II) Dalam Larutan Pada Abu Dasar Batu Bara Menggunakan Metode Kolom. Prosiding Kimia FMIPA ITS: Surabaya.

[12] Susanawati, D.L.; Bambang, S.; dan Kustamar. 2011. Penurunan Kandungan Logam Berat Pada Air Lindi Dengan Media Zeolit Menggunakan Metode Batch Dan Metode Kontinyu. Jurnal AGROINTEK. Vol. 5, No. 2. Malang. 